Article

\title{
Exploring Bottled Water Purchase Intention via Trust in Advertising, Product Knowledge, Consumer Beliefs and Theory of Reasoned Action
}

\author{
Carolyn A. Lin ${ }^{1, *}$ and Xiaowen $\mathrm{Xu}^{2}$ \\ 1 Department of Communication, University of Connecticut, 337 Mansfield Road, Storrs, \\ Mansfield, CT 06269, USA \\ 2 Department of Strategic Communication, Butler University, 4600 Sunset Ave, Indianapolis, IN 46208, USA; \\ xxu4@butler.edu \\ * Correspondence: carolyn.lin@uconn.edu
}

Citation: Lin, Carolyn A., and Xiaowen Xu. 2021. Exploring Bottled Water Purchase Intention via Trust in Advertising, Product Knowledge, Consumer Beliefs and Theory of Reasoned Action. Social Sciences 10: 295. https://doi.org/10.3390/ socsci10080295

Academic Editor: Barry Smart

Received: 7 June 2021

Accepted: 30 July 2021

Published: 5 August 2021

Publisher's Note: MDPI stays neutral with regard to jurisdictional claims in published maps and institutional affiliations.

Copyright: (c) 2021 by the authors. Licensee MDPI, Basel, Switzerland. This article is an open access article distributed under the terms and conditions of the Creative Commons Attribution (CC BY) license (https:/ / creativecommons.org/licenses/by/ $4.0 /)$.

\begin{abstract}
As the bottled water market is projected to grow continuously worldwide, so is the plastic waste that pollutes the environment. The beverage industry's marketing campaigns have played an important role in sustaining the popularity of bottled water. Social science theory-based empirical research examining how consumers make bottled water consumption decisions remains limited. To help fill this literature gap, the current study tested a conceptual framework to explore the influence of trust in bottled water advertising and perceived product knowledge on consumer beliefs about bottled water, in conjunction with theory of reasoned action. The study surveyed a sample of college students in the U.S. $(\mathrm{N}=445)$. Findings showed that greater trust in bottled water advertising as well as more false knowledge and less factual knowledge were significantly related to consumer beliefs about bottled water's product content and image. Furthermore, more favorable cognitive beliefs, affective beliefs, attitude and perceived subjective norms toward bottled water consumption were positively related to purchase intention. To reduce bottled water purchase among young adults, it would be beneficial to utilize marketing strategies to popularize and normalize carrying a reusable water bottle as an environmentally friendly habit and a preferred lifestyle choice.
\end{abstract}

Keywords: trust in advertising; affective beliefs; bottled water consumption; cognitive beliefs; product knowledge; theory of reasoned action

\section{Introduction}

Over the past decade, the bottled water market has witnessed an annual growth rate of 5\% each year (Johnson 2019). Consumption of bottled water surpassed the per capita consumption of carbonated soft drinks in 2016, for the first time in the U.S. (Maloney 2017). In 2019, per capita consumption of bottled water reached roughly 43.7 gallons in the United States; by comparison, only about $10 \%$ of Americans reported that they drank tap or filtered water exclusively in 2018 (Conway 2020). The global bottled water market size is expected to reach USD 505.19 billion by 2028 (PR Newswire 2021). Although the recent COVID pandemic has left homebound consumers buying fewer bottles of water, leaving the bottled water industry with a slight decline in revenues, the U.S. is still the largest bottled-water-consuming country in the world (Abboud and Evans 2020).

As bottled water is packaged in polyethylene terephthalate (PET) bottles, the discarded bottles are a constant source of environmental pollution. Research has shown that harmful toxic chemicals such as antimony can leach from these PET bottles to poison the earth and sea (Alabi et al. 2019; Shotyk et al. 2006). Recycling rate of PET and jars was $29.1 \%$ in the U.S. in 2019 (United States Environmental Protection Agency 2021). While caps and lids from PET bottles are among the top three common types of ocean debris (Chung 2020), only $8.4 \%$ of the plastic waste was recycled in the U.S. and the rest was left behind as landfills in 
2017 (Peçanha 2020). Of the recycled bottles, a very small percentage are used to make new bottles. For example, Coca Cola and Nestlé Waters North America produced only $7 \%$ and $6 \%$ of their plastic from recycled material, respectively (TAPP Water 2018).

According to a large national study using a stratified random sample of U.S. adults, younger adults were more likely to drink bottled water than their older counterparts (Hu et al. 2011). Another study examining the data collected for the National Health and Nutrition Examination Survey (in three waves during 2011-2016) found that American adults aged 30-50 consumed more bottled water than those aged 19-30; these results, however, were not adjusted through sample weighting, as the sample size for the former was 1.56 times larger than the latter (Vieux et al. 2020).

As for college student studies, a 2016 national study of Generation Z college students (those born after 1996) showed that $42 \%$ of them planned to drink more bottled water and $22 \%$ only drank bottled water (Buzalka 2016). Based on this study, the top reasons for purchasing bottled water included: "all-natural," "low-calorie," "organic," "vitaminenhanced" and "zero-calorie." Similar findings were demonstrated in a follow-up 2018 national study, which indicated that bottled water remained the most favorite beverage among Gen $\mathrm{Z}$ college students, as nearly $44 \%$ of them reported drinking seven or more servings each week (Sudano 2018).

Even so, a national poll conducted by Pew Research 2020 showed that $77 \%$ of the American young adults (ages 18-29) considered environmental protection to be a top national priority. A subsequent Pew Research study also reported that more Gen Zers considered climate change a top personal concern than any other cohorts (Tyson et al. 2021). These polling results appeared to reflect the public's sentiment associated with perceived safety of drinking water in the U.S. Specifically, a Gallup poll indicated that more Americans expressed a "great deal" of concern with pollution of drinking water $(63 \%)$ and water ways (i.e., rivers, lakes and reservoirs) (57\%) than all other environmental concerns (McCarthy 2017). The same study also reported that $80 \%$ of non-Whites and $75 \%$ of low-income Americans were worried about drinking-water pollution, compared to $56 \%$ Whites and $56 \%$ higher-income individuals.

Extant literature on bottled water research primarily contains work that studied topics related to environmental research, science education, natural resource management and similar areas. Social scientific theory-based empirical research addressing bottled water use behavior remains limited (Jovarauskaite et al. 2020). The current study aims to help fill this theoretical and empirical gap by integrating a set of antecedent cognitive and affective factors with theory of reasoned action (TRA) to explain bottled water consumption intention. Similar to the approach adopted in previous research that applied the TRA framework (e.g., Bagozzi et al. 1992; Fitzmaurice 2005; Langdridge et al. 2007), this study measured antecedent variables relevant to bottled water marketing and consumption in conjunction with the TRA constructs in the context of consumer decision-making. Specifically, this study aims to investigate two major theoretical questions regarding bottled water perceptions and purchase decision-making: (1) how trust in advertising and bottled water knowledge influence cognitive and affective beliefs toward bottled water; and (2) how consumer knowledge and beliefs impact their attitude and perceived social norms to explain their purchase intention.

\subsection{Literature Review}

For consumers, advertising is a major source of product information about bottled water (hereafter, BW). For example, Fiji water promotes its brand with social media hashtags such as \#EarthsFinest; its television commercials feature statements-such as "Untouched by man. It's earth's finest water" - accompanied with images of innocent-looking children in a serene tropical location. However, as pointed out by Jones et al. (2017), "FIJI Water is not from a source surrounded by a tropical rainforest or the sort of coastal or floral environments evident on their packaging...FIJI Water's glamorous packaging bears little resemblance to the environmental reality that at its source point" (pp. 119-20). 


\subsection{Trust in BW Advertising}

Trust in advertising is a concept that extends beyond being a dimension of the perceived credibility construct, as it includes additional components such as perceived benevolence and willingness to rely on others (e.g., Doney and Cannon 1997; McAllister 1995). As suggested by Soh et al. (2009), "The willingness to act on advertising is considered a more appropriate indicator of trust in advertising than actual trusting behavior" (p. 86). The general concept of trust in advertising or advertising trust is usually conceptualized as "accuracy" or integrity of advertising, as delineated from falsehood in advertising, and has been commonly evaluated with a single-item measure (e.g., Menon et al. 2002; Obermiller and Spangenberg 1998; Soh et al. 2009). As a primary function of advertising is to enable consumers to evaluate brand/product information to help them make a consumption choice (e.g., Nelson 1974), lacking alternative information sources can lead to reliance on advertising information to make that choice.

Martin (2003) reported that advertising was the most common source for learning about BW's quality and production process among college students, followed by friends/family, classes/lectures, and scientific literature. Islam and Habib (2009) suggested that brand advertising was an important aspect influencing intention to purchase BW products. Etale et al. (2018) contended that advertising messages, which typically depict BW as a product synonymous with youthfulness, energy, trendiness and social status, could result in higher consumption intention. Prasetiawan et al.'s (2017) study conducted in the Indonesian market suggested that substantial marketing efforts highlighting BW's appeal via desired good quality, convenience and health benefits had resulted in high trust in BW as a product. Similarly, BW information learning and brand familiarity due to repeated exposure to advertising messages can help build consumer trust in a product, which can translate into purchase intention and behavior (Ha and Perks 2005).

In 2019, BW advertising expenditure ranked third in total beverage advertising, trailing behind beer and carbonated soft drinks (International Bottled Water Association n.d.). While the primary information source for learning about a BW brand/product for college students is advertising, research has found that college students lack factual knowledge about the content of BW and its environmental impact (Saylor et al. 2011). Other research has also shown that college students' knowledge about drinking water was low (Johnson and Courter 2020). This lack of factual knowledge is not surprising, as bottled water advertising campaigns have helped create and shape misapprehension and false knowledge about BW products among consumers (Klein and Huang 2008; Wilk 2006).

For example, Nestlé's Poland Spring advertising campaigns have falsely claimed that ice mountain water is the only source of their product, instead of filtered tap or well water (Macias 2018; Prevos 2013; Stempel 2019). Even though Nestlé's false advertising claim (e.g., "Filtered through the 10,000-year-old glacial aquifers of Maine, Poland Spring has natural electrolytes for a crisp and refreshing taste") has been subjected to repeated legal challenges, the company was still ranked 29th in the top 100 most reputable companies in 2021-along with two other largest BW producers-the 58th-ranked Coca Cola and 20th-ranked Pepsi Corp (The 2021 Axios Harris Poll 100 2021). In essence, the marketing machine of these large beverage companies has been able to establish strong brand trust among consumers.

Based on the empirical evidence discussed above, it is reasonable to speculate that greater trust in BW advertising could be related to false knowledge about BW product (e.g., purity and health benefits) and the opposite could also be true for factual knowledge (e.g., negative environmental impact) about BW. To empirically test the potential connection between trust in BW advertising and BW knowledge, two research questions are posed below.

RQ1a-b: Will trust in BW adverts be (a) positively related to false BW knowledge, and (b) negatively related to factual BW knowledge? 


\subsection{Consumer Beliefs}

To examine consumer beliefs about BW, the current study conceptualizes this construct via two different dimensions: cognitive vs. affective dimensions. The theoretical relevance of each of these conceptual dimensions is discussed below.

Cognitive Beliefs. Cognitive beliefs refer to individuals' evaluative responses about an attitude object based on their beliefs (Manstead and Parker 1995; van der Pligt et al. 1997). Advertisers constantly promote BW (an "attitude object") as a product with "pure," "healthy" and "protected" quality (usually with images of beautiful mountains and springs) against tap water's "inconsistent" and "unpredictable" quality (Ferrier 2001; Prevos 2013; Whitman 2016). Numerous advertising campaigns have helped create the beliefs that BW contains health benefits that tap water does not (Hu et al. 2011; Johnstone and Serret 2011; Ward et al. 2009). Past studies have also revealed that college students consumed a lot of bottled water because they perceived bottled water as providing additional health benefits relative to tap water, even though they could not name those benefits when questioned (e.g., Ward et al. 2009). As such, advertising has shaped consumer perceptions or cognitive beliefs of BW quality, in terms of its greater purity, cleanliness, taste and even nutritional values, when compared to tap water (Geerts et al. 2020; Ballantine et al. 2019; Klein and Huang 2008; Wilk 2006).

Affective Beliefs. Affective beliefs reflect individuals' evaluative responses, based on emotional and affective reactions engendered by an attitude object (Ballantine et al. 2019; Manstead and Parker 1995; van der Pligt et al. 1997). Major BW marketers often depict their BW products (an "attitude object") as a status symbol or desirable consumer identity, coupled with innovative packaging design such as bottle shape and labeling (Islam and Habib 2009). Etale et al. (2018) argued that bottled water advertising messages promoting an image of youthfulness, energy, trendiness and social status have been successful in eliciting positive affective responses and stimulating consumption intention. Biro's (2019) study of a restaurant's water menu (made available at a dinning establishment), is an example of the social status prescribed by different branded water to its patrons. Similarly, Brewis et al.'s (2021) reported that when consumers in a large U.S. city were asked to consider and rank different models of water consumption, Fiji-brand water emerged as the most prestigious type of drinking water across the "bottled water lover" model, "technology positive" (nanotechnology- and RO-treated water) model, and the "elitist anti-tap" model.

As little empirical research on the association between trust in BW advertising and consumer beliefs is available, two research questions are proposed to ascertain their relationship.

RQ2a-b: Will trust in advertising be positively related to (a) cognitive beliefs and (b) affective beliefs about BW consumption?

\subsection{Consumer Knowledge}

Consumer knowledge refers to a consumer's broad familiarity resulting from their accumulated consumption experiences, while product knowledge (a subset of consumer knowledge) reflects the actual or perceived sum of product class information and rules stored in their memory (Philippe and Ngobo 1999). As the current study assumes that trust in BW advertising could help formulate either factually accurate or inaccurate consumer/product knowledge, such knowledge is also expected to have an impact on consumer beliefs about BW consumption.

For example, factual knowledge about bottled water was found by Martin (2003) to be negatively related to bottled water consumption frequency among college students; the same was true for factual knowledge about the safety and quality of tap water. Foote (2011), however, failed to find a similar relationship and suggested that factual knowledge had little effects on BW consumption decisions instead. Xu and Lin's (2018) study of college students yielded mixed results and confirmed only selected findings from these prior 
studies, suggesting that BW knowledge was negatively related to tap water consumption but irrelevant to BW consumption.

On the other hand, Saylor et al.'s (2011) study demonstrated that college students who preferred tap water were aware that most bottled water is not necessarily drawn from a "natural" or "more pure" water source, when compared to tap water; students also recognized that water source disclosure is missing on product labels and that plastic bottles can cause environmental pollution. van der Linden's (2013) study tested environmental messages with a college student sample and found that knowing the facts about the bottled water product itself-including the water supply source and manufacturing process—could potentially discourage students' BW consumption behavior.

Empirical evidence on the effects of false or factual knowledge on consumer beliefs is largely lacking. Insufficient empirical evident notwithstanding, it would be logical to assume that more factual knowledge about BW could negatively influence rational cognitive beliefs (e.g., function-based) about BW consumption, but more false knowledge about BW could positively influence affective beliefs (e.g., image-based). To verify these assumptions, the following two research questions will be tested.

RQ3a-b: Will (a) factual knowledge be negatively related to cognitive beliefs about BW, and (b) false knowledge be positively related to affective beliefs about BW?

\subsection{Consumer Beliefs and Theory of Reason Action}

According to Theory of Reasoned Action (Ajzen 1985, 1991), intention to perform a behavior is a function of both attitude and subjective norms associated with that behavior; behavioral intention could further lead to actual behavior. While attitude is shaped by the beliefs and affective evaluation of behavioral outcomes, subjective norm reflects the normative beliefs of expectations from important others. Past research has applied theory of reasoned action (TRA) to study pro-environmental behaviors-such as global climate change (Kim et al. 2013), water conservation (Trumbo and O'Keefe 2005; Untaru et al. 2016) and green consumerism (Coleman et al. 2011) — but not bottled water consumption behavior. The ensuing discussion will review TRA in relation to BW consumption decision-making process.

As discussed above, advertising campaigns could influence consumer trust, knowledge and beliefs about water BW consumption. By extension, consumers' cognitive and affective beliefs, built on trust and knowledge about BW, could then potentially influence their attitude toward the product. For instance, Cote and Wolfe's (2018) content analysis study suggested that BW adverts and pro-BW campaigns associate the product with positive emotional appeals to (1) support consumers' self-esteem, (2) provide them with opportunities to engage in worldview defense through misleading environmental responsibility and local-community supportiveness messages, and (3) symbolically extend the consumers' perceived lifespan (i.e., quality and pure water leads to longevity).

These findings are consistent with past studies, which reported that advertising could shape consumer perceptions of BW quality, including cleanliness, taste, nutritional values, health benefits and safety (e.g., Klein and Huang 2008; Ward et al. 2009; Jovarauskaite et al. 2020). This type of cognitive beliefs could then influence consumer attitude and purchase intention toward BW products. By the same token, consumer beliefs about bottled water brands could be shaped by their evaluation of affect-targeted appeals that convey a BW brand's image, status symbol, packaging design and pricing through advertising (Islam and Habib 2009). This type of affective beliefs could also have an influence on consumer attitude toward BW, which could lead to BW purchase intention.

As aforementioned, misleading information permeated through advertising messages about BW as a high-quality and safe choice preferred by consumers has helped create positive cognitive beliefs about BW consumption (Klein and Huang 2008; Ward et al. 2009; Jovarauskaitè et al. 2020). Advertising campaigns have also been found to lead a majority of consumers to believe BW's superiority over tap water (e.g., Hu et al. 2011). Marketing messages have pitched BW consumption as a social status-conferral purchase to project a 
prestigious, cool and fun consumer image/identity to help shape positive affective beliefs about BW consumption (Cote and Wolfe 2018; Etale et al. 2018; Islam and Habib 2009). In essence, BW advertising portrays a lifestyle image or identity that the consumers may wish to project about themselves; this image or identity presents BW as a product that communicates youthfulness, energy, trendiness and social status (Etale et al. 2018).

Hawkins (2017) argued that mass marketing in the 1990s promoted a "hydration support" norm, which encouraged consumers to drink as much water as possible for better health, via purchasing and carrying BW around all the time. He further advanced an observation which encapsulated how the influence of BW marketing campaigns on consumer beliefs-via the superiority of BW over tap water-had helped shape BW consumption norm as follows: "Bottles are normalizing new modes of water governance that foreground the tensions between water as an individualized market good and water as a collective service." (p. 2). Combining these respectively favorable cognitive and affective beliefs about BW as a healthy product and a preferred lifestyle-product choice, it is reasonable to assume that these consumer beliefs could also help contribute to the perception that BW consumption is an acceptable, supported and/or desirable social norm.

Few (if any) studies have examined how consumer beliefs might have contributed to their attitudes and perceived social norms toward BW consumption. Nonetheless, the extant literature has validated how cognitive and affective beliefs could impact the consumption of sustainable goods. For example, Polish consumers reported that they would not purchase a "green" clothing product, if the clothing item did not provide enough aesthetic benefits to satisfy their aspirations (Rahman and Koszewska 2020). Another study that compared Canadian and Indian consumers also reported that consumers were more interested in psychic/aesthetic (e.g., style and color) and physical/functional (e.g., comfort and durability) cues than extrinsic and sustainable (e.g., price, brand name and eco-ethical labels) cues (Rahman et al. 2021).

Based on the prior work discussed above that connects consumer beliefs and TRA, the following hypotheses are postulated to validate whether consumers' cognitive and affective beliefs about BW will be related to their attitude, perceived social norms and purchase intentions associated BW consumption.

Hypothesis 1a-c (H1a-c). Cognitive beliefs will be positively related to (a) attitude and (b) perceived subjective norms, and (c) purchase intention associated with BW consumption.

Hypothesis 2a-c (H2a-c). Affective beliefs will be positively related to (a) attitude, (b) perceived subjective norms, and (c) purchase intention associated with BW consumption.

\subsection{BW Attitudes, Consumption Norms and Purchase Intention}

Meta-analyses on environmental behavior (Bamberg and Möser 2007; Klöckner 2013; Morren and Grinstein 2016) indicated a relatively stable and positive relationship between attitude and behavioral intention $\left(r_{-} z=0.60-0.66\right)$ across various types of environmentally friendly behaviors (e.g., recycling, water conservation, energy saving, and sustainable consumption). Existing research testing the TRA theory via the influence of attitude and perceived norms on BW consumption intention and behavior is scare, however.

Of the limited empirical research that tested consumer attitudes, Levallois et al. (1999) reported that negative attitude toward tap water quality was a determinant for selecting BW as an alternative to tap water. Islam and Habib (2009) maintained that attitude toward the brand's status symbol, attractive packaging design and brand advertising are important affective factors that influenced intention to purchase BW products. Qian's (2018) study of college students across Hong Kong, Macau and Singapore similarly reported that positive attitude toward BW products was related to more frequent purchase behavior. To confirm the relations between BW attitude and purchase intent herein, the following hypothesis is posited. 
Hypothesis 3 (H3). Attitude toward BW consumption will be positively related to BW purchase intention.

Of the few available studies that referenced social influence, Martin's (2003) work demonstrated that peer pressure was a factor that could play a role in increasing BW consumption. Likewise, perceived subjective norms were found to predict increased green products purchasing (Al-Swidi et al. 2014), household waste recycling (Ar1 and Veysel Yilmaz 2016; Ahmad et al. 2016) and household water consumption (Jorgensen et al. 2009). van der Linden (2013) revealed that Dutch college students exposed to a campaign message of BW's negative environmental impact and decreased BW consumption among their peers reported lower BW purchase intention. Another U.S. college student study also revealed that perceived positive subjective norms toward BW consumption contributed to BW purchase intention (Xu and Lin 2018). Moreover, a positive correlation between BW consumption and perceived subjective norms was found across three subdimensions-personal habits, family habits and environmental concerns-among college students from three different East Asian regions (Qian 2018). To further verify whether perceived subjective norms on BW consumption may influence purchase intention, the following hypothesis is proposed.

Hypothesis $4 \mathbf{( H 4 ) . ~ P e r c e i v e d ~ s u b j e c t i v e ~ n o r m s ~ t o w a r d ~ B W ~ c o n s u m p t i o n ~ w i l l ~ b e ~ p o s i t i v e l y ~ r e l a t e d ~}$ to $B W$ purchase intention.

\subsection{Proposed Conceptual Model}

A conceptual model is proposed below to integrate the hypotheses and research questions stated above (see Figure 1). The model illustrates that trust in BW advertising is related to BW knowledge (factual vs. false) and the latter is associated with cognitive and affective beliefs. It also demonstrates how cognitive and affective beliefs are connected to attitude and perceived subjective norms toward BW consumption and purchase intention.

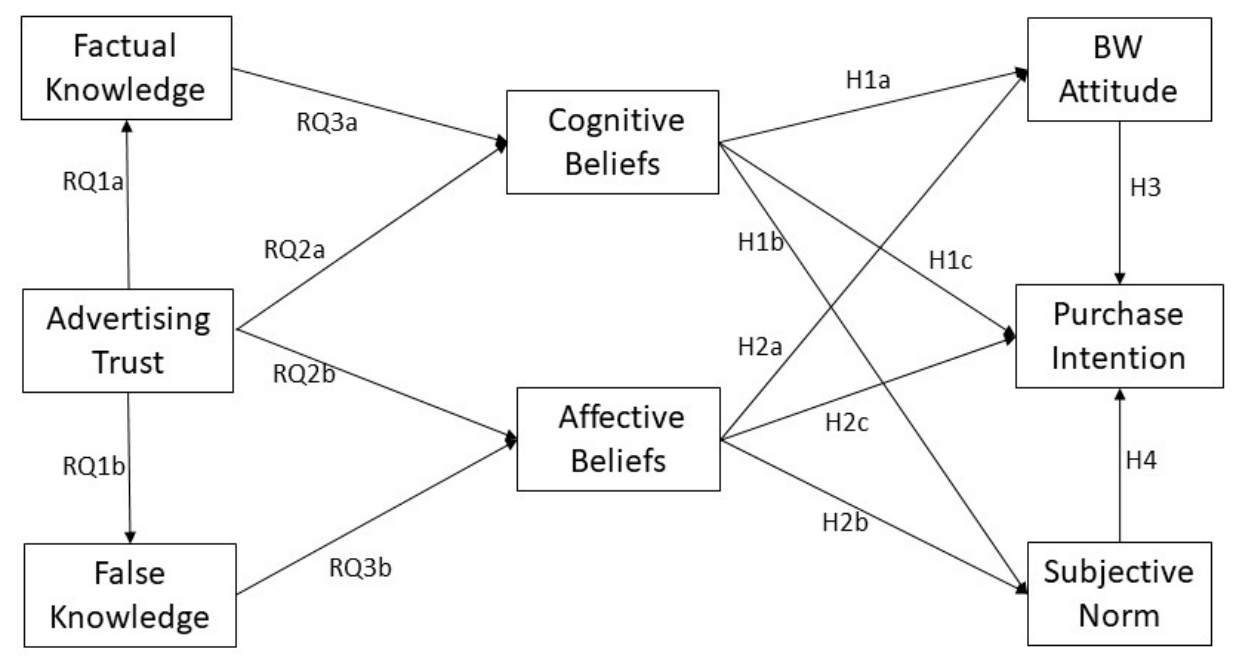

Figure 1. Proposed Advertising and Knowledge Conceptual Model.

\section{Material and Methods}

\subsection{Study Sample and Procedure}

An online survey was conducted with a sample of college students recruited from an introductory-level general education course at a large northeastern university, with prior IRB approval. Extra course credit was offered to those students who participated in the study. As BW marketing typically targets the young adult population (Hu et al. 2011), college students who have begun to make consumption decisions independently as emerging adults are a suited population for studying BW consumption behavior. College students 
were also chosen for this study because they reportedly consumed 7.7 single-use bottles of water (500 mL bottle) on average per week (Saylor et al. 2011).

Students who wished to participate in the study were invited to first log onto the study webpage to review the informed consent form. After expressing their consent, they responded to the survey questions measuring the variables tested in the H's and RQ's stated above, along with a set of demographic questions. The study sample yielded 445 valid cases, after removing the cases that had incomplete answers. Average age of the sample was $19.2(\mathrm{SD}=1.3), 48 \%$ of which were males. The racial/ethnic breakdown of the sample is as follows: Caucasians (68.9\%), African Americans (7\%), Hispanics $(7.2 \%)$, Asians (12.8\%), Pacific Islanders (0.5\%), Native Americans ( $0.2 \%)$, two or more races $(2.3 \%)$ and other $(1.1 \%)$. In terms of the BW consumption behavior of study participants, $39 \%$ of the them reported drinking at least 5 bottles and $27 \%$ indicated consuming at least 7 bottles each week. With regard to drinking-water preference, $47 \%$ of them expressed a preference of bottled water over other types of water, $9.3 \%$ favored tap water instead, and $43 \%$ had no preference.

\subsection{Measures}

All study measures are presented in Appendix A. Trust in BW adverts was assessed by a single item on a seven-point scale (ranging from $1=$ "don't trust all" to $7=$ "totally trust"), following the measurement approach validated in the literature (e.g., Menon et al. 2002; Obermiller and Spangenberg 1998; Soh et al. 2009). Participants were instructed to consider how much they trust the information originated from BW product advertisements (e.g., Dasani, Poland Spring, Evian, and Fiji). Cognitive Beliefs were measured with five items adapted from previous research (e.g., Doria et al. 2009; Islam and Habib 2009; Ward et al. 2009) to indicate consumers' evaluation of BW product source and quality, on a sevenpoint scale (ranging from $1=$ "strongly disagree" to $7=$ "strongly agree"). Sample items include describing bottled water as follows: "It tastes good," "It is clean," and "It contains ingredients good for health." These items were combined to form a composite variable $($ Alpha $=0.86)$. Affective beliefs were reflected with three items adapted from previous research (e.g., Doria et al. 2009; Islam and Habib 2009; Ward et al. 2009) to describe how the product makes the consumer feel, on a seven-point scale (ranging from 1= "strongly disagree" to $7=$ "strongly agree"). These items include the following: "It looks cool to carry a store-bought bottled water around," "I like the shape/design of the store-bought bottle," and "I like the reputation of bottled water brands/companies." A composite variable merging these three items has an Alpha value of 0.85 .

Seven items were developed to describe false knowledge, including six original items and one adapted item ("Bottled water is originated from spring water in nature.") based on Foote's (2011) measures of "environmental knowledge of bottled and tap water." Another seven items were constructed to illustrate factual knowledge, including six items adopted from Foote (2011) and one original item ("Three of five single-use water bottles are recycled in U.S."). Participants evaluated each item with a true/false response. A false knowledge index was created to sum up the number of inaccurate statements that participant considered to be true. Examples of these items include: "Bottled water is originated from spring water in nature," "Most people prefer bottled water over tap water," and "Single-use bottled water is different from tap water." A factual knowledge index was also generated to total up the number of accurate statements that were correctly identified. Examples of these items include "The cost of getting an annual supply of bottled water is about 100 times more than that for the same amount of tap water," "Producing disposable plastic water bottles requires the use of millions of barrels of oil," and "Over half of bottled water sold in the U.S. is tap water."

Subjective norms were gauged with four original items constructed to assess perceived norms of BW consumption approved by one's social circle on a seven-point scale (ranging from $1=$ "strongly disagree" to $7=$ "strongly agree"). Participants evaluated the following perceived norms from their social circle associated with single-use bottled water: 
(1) approval of frequent consumption, (2) discouragement from purchasing (reverse coded),

(3) support of their preference, and (4) displeasure with their spending (reverse coded). These items were then merged to construct the composite variable (Alpha $=0.91$ ).

Attitude was indicated with five original items on a seven-point scale (ranging from $1=$ "strongly disagree" to $7=$ "strongly agree"). Sample items include whether consuming single-use bottle water (1) suits my lifestyle, and (2) makes me feel good about myself. These five items were averaged to create a composite variable (Alpha $=0.90)$. Purchase Intention was evaluated with ten original items that indicate ten different locations / scenarios for consuming bottled water, measured on the same seven-point scale $(1=$ "strongly disagree" to 7 = "strongly agree"). Sample items include reporting the intention to purchase bottled water when participants "exercise in the gym," "attend outdoor events," and "stop at a convenient store." These items were averaged to form a composite variable (Alpha $=0.92)$.

\section{Results}

A structural equation modeling (SEM) analysis was used to test the research hypothesis and questions. The measurement model statistics showed that the model fit was acceptable, $\chi^{2}=683.94, \mathrm{CMIN} / \mathrm{DF}=2.28, p<0.001 ; \mathrm{CFI}=0.95, \mathrm{IFI}=0.95 ; \mathrm{RMSEA}=0.05$. All factor loadings were above 0.63 . Based on these results, exploratory factory analysis was conducted to confirm the factor structure of each composite variable and its reliability (as reported in the measures section above). Table 1 presents both descriptive and correlation statistics. All variables were significantly correlated. Correlation between BW attitude and purchase intention was at 0.68 ; the confirmatory factory analysis established that there was no multicollinearity concern.

Table 1. Correlations and Descriptive Statistics.

\begin{tabular}{|c|c|c|c|c|c|c|c|c|}
\hline & 1 & 2 & 3 & 4 & 5 & 6 & 7 & 8 \\
\hline 1 Trust in Advertising & & & & & & & & \\
\hline 2 False Knowledge & $0.40^{* *}$ & & & & & & & \\
\hline 3 Factual Knowledge & $-0.24^{* *}$ & $-0.42^{* *}$ & & & & & & \\
\hline 4 Cognitive Beliefs & $0.42^{* *}$ & $0.38 * *$ & $-0.25^{* *}$ & & & & & \\
\hline 5 Affective Beliefs & $0.29^{* *}$ & $0.24 * *$ & $-0.18^{* *}$ & $0.35 * *$ & & & & \\
\hline 6 Attitude toward BW & $0.37^{* *}$ & $0.31 * *$ & $-0.26^{* *}$ & $0.46 * *$ & $0.38 * *$ & & & \\
\hline 7 Subjective Norm & $0.32 * *$ & $0.23 * *$ & $-0.27 * *$ & $0.35 * *$ & $0.21 * *$ & $0.33 * *$ & & \\
\hline 8 Purchase Intention & $0.36^{* *}$ & $0.29 * *$ & $-0.30 * *$ & $0.49 * *$ & $0.37 * *$ & $0.68 * *$ & $0.44^{* *}$ & \\
\hline$M(S D)$ & $\begin{array}{c}4.03 \\
(1.45)\end{array}$ & $\begin{array}{c}3.90 \\
(1.31)\end{array}$ & $\begin{array}{c}4.58 \\
(1.45)\end{array}$ & $\begin{array}{c}4.90 \\
(1.20)\end{array}$ & $\begin{array}{c}2.87 \\
(1.42)\end{array}$ & $\begin{array}{c}3.59 \\
(1.34)\end{array}$ & $\begin{array}{c}4.49 \\
(1.25)\end{array}$ & $\begin{array}{c}3.95 \\
(1.39)\end{array}$ \\
\hline
\end{tabular}

** $p<0.01$.

A path analysis was utilized to test the proposed research questions and hypothe-ses (see Figure 2). The modeling statistics suggested that the model was a good fit, $\chi^{2}=10.71$, $\mathrm{DF}=6, \mathrm{CMIN} / \mathrm{DF}=1.79, p=0.10 ; \mathrm{CFI}=0.995, \mathrm{IFI}=0.995, \mathrm{NFI}=0.99 ; \mathrm{RMSEA}=0.04$, but one proposed path was not statistically significant: between "affective beliefs" and "subjective norms." After removing this non-significant path, a revised model also demonstrated a good model fit, $\chi^{2}=12.29, \mathrm{DF}=7, \mathrm{CMIN} / \mathrm{DF}=1.76, p=0.09 ; \mathrm{CFI}=0.99, \mathrm{IFI}=0.99$, $\mathrm{NFI}=0.99$; RMSEA $=0.04$. The overall equation explained $53 \%$ of the total variance in intention toward BW consumption. 




Figure 2. Path Model Results. ${ }^{*} p<0.05,{ }^{* *} p<0.01,{ }^{* * *} p<0.001$.

RQ1a-b query whether trust in BW advertising is associated with factual and false BW knowledge. Results showed that trust in advertising was a negative predictor of factual knowledge $(B=-0.24, p<0.001)$ and a positive predictor of false knowledge $(\mathrm{B}=0.40, p<0.001)$, as anticipated. Per the query of RQ2a-b, the study tested whether trust in BW advertising is positively related to cognitive belief and affective belief about BW consumption. As expected, trust in advertising was found to be a positive predictor of both cognitive beliefs $(\mathrm{B}=0.38, p<0.001)$ and affective beliefs $(\mathrm{B}=0.23, p<0.001)$. RQ3a asks whether false knowledge is positively related to affective beliefs about BW consumption. Findings indicated that false knowledge was a positive predictor of affective belief $(B=0.15$, $p=0.002$ ). By contrast, $\mathrm{RQ} 3 \mathrm{~b}$ aims to attest the potential negative relationship between factual knowledge and cognitive beliefs about BW consumption. Factual knowledge emerged as a significant and negative predictor of cognitive beliefs $(B=-0.15, p<0.001)$.

$\mathrm{H} 1 \mathrm{a}-\mathrm{c}$ propose that stronger cognitive beliefs about BW benefits will be related to more favorable attitude and subjective norm, as well as greater purchase intention toward BW. Results revealed that cognitive beliefs positively predicted attitude $(\mathrm{B}=0.30, p<0.001)$, subjective norm $(B=0.22, p<0.001)$, and purchase intention $(B=0.16, p<0.001)$, validating $\mathrm{H} 1 \mathrm{a}-\mathrm{c}$. H2a-c presume that stronger affective beliefs about BW benefits will be related to more favorable attitude and subjective norm, as well as greater purchase intention toward BW. Findings showed that affective beliefs was a positive predictor of attitude $(\mathrm{B}=0.22$, $p<0.001)$ and purchase intention $(B=0.08, p=0.02)$, but not subjective norms $(B=0.06$, $p=0.21)$. Hence, while H1a and H1c were supported, H1b was not.

H3 states that attitude toward BW will be positively related to purchase intention. As attitude was found to be a positive predictor of purchase intention $(\mathrm{B}=0.51, p<0.001)$, this hypothesis was supported. $\mathrm{H} 4$ asserts that there will be a positive relationship between perceived subjective norm and purchase intention. This positive relationship was validated $(\mathrm{B}=0.19, p<0.001)$, providing support for $\mathrm{H} 4$.

\section{Discussion}

The current study makes an important theoretical contribution to the literature, as it is among the first to provide a conceptual framework that identifies and validates a set of theoretical constructs to help explain how young adults make BW purchase decisions. Study results have advanced our theoretical understanding of how trust in BW advertising is related to consumer knowledge and beliefs about BW product attributes-as well as how such beliefs along with consumer attitudes and perceived norms-could help explain BW purchase intention. Specifically, the proposed conceptual framework integrated relevant cognitive, affective and behavioral measures with the constructs of TRA. The structural model which tested the conceptual model accounted for $53 \%$ of the variance in BW purchase intention. 
The current study theorized and validated the role of trust in BW adverts in influencing consumer knowledge and beliefs about BW products. This conceptual approach is different from what was commonly adopted in the extant literature, which typically measured advertising exposure frequency to explain how consumers might acquire product perceptions/beliefs (e.g., Klein and Huang 2008; Wilk 2006). As suggested by the findings, trust in BW advertis was also relevant to both rational and emotional thoughts about BW products. In particular, those who trusted BW adverts more also held a stronger level of cognitive beliefs about BW's functional quality (e.g., purity, cleanliness, health and/or safety) and affective beliefs about BW's symbolic value (e.g., fun, cool, prestigious and/or social status).

These findings hence provided preliminary evidence to validate our assumption that trust in BW advertising could influence how consumers think and feel about BW products. Not surprisingly, BW marketers relentlessly reinforce the beliefs that BW is superior to tap water and represents a desired lifestyle choice. Such marketing efforts appears to have been relatively effective, as two of the top reasons for purchasing BW products among college students were "all-natural" and "organic" (Buzalka 2016). Likewise, social symbol was found to be related to consumer preference of BW as their drinking water (e.g., Etale et al. 2018; Islam and Habib 2009). Furthermore, the current study revealed that perceived trust in BW advertising was a positive predictor of false BW knowledge and a negative indicator of factual BW knowledge. This suggests that when consumers trust the BW advertising content more, they could also have more misapprehensions about BW products, and vice versa.

The relationship between consumer knowledge and beliefs showed us that BW knowledge contributed to explain cognitive and affective beliefs about BW consumptions. Interestingly, while factual knowledge was negatively related to consumers' cognitive beliefs, false knowledge was positively related to their affective beliefs. Hence, the more factual knowledge that consumers possessed, the more strongly that they disagreed with the functional attributes promoted in BW advertising. On the other hand, when consumers had more false knowledge, they more strongly embraced the symbolic meanings asserted in BW advertising.

The significance of affective beliefs evidenced here is consistent with the work of Brio and Brewis et al. (2021), which demonstrated how BW's symbolism is related to consumer beliefs about BW preference and consumption. From a physiological perspective, a study that utilized electrophysiological responses to examine purchase tendency for hedonic and utilitarian products (Chen et al. 2019) found that those with a low social status had a strong tendency to prefer hedonistic products associated with symbolic status meaning. By comparison, those with a high social status did not show any preference between these two types of products.

In terms of perceived social norms, as cognitive beliefs were found to be positively related to perceived subjective norms of BW consumption, the same was not true for affective beliefs. These results suggest that while more positive beliefs about BW's functional value are associated with more favorable perception of BW consumption norms in one's inner circle, more positive beliefs about BW's symbolic value are irrelevant to such social norm perception. It is possible that consumers who hold a stronger belief about BW's status-conferral-related claims may not wish to associate such seemingly "superfluous" beliefs with social approval. These findings thus help signify the need for shifting the social norms away from habitual BW consumption to drinking water from a reusable water bottle. Specifically, past work has found the combined message of social norming and environmental conservation aiming to reduce BW drinking intentions among college students was effective in an experimental study setting (van der Linden 2013). Likewise, a study that utilized an approach of institutional "norm-signaling" of a "prototypical behavior" - carrying drinking water in a university-issued reusable water bottle-also appeared to contribute to a decrease of BW purchase frequencies among college students (Santos and van der Linden 2017). 
As hypothesized, cognitive beliefs about BW's quality-related attributes were shown to be positively related to purchase intention. This finding verified prior study results, which demonstrated favorable perceptions about the quality and health benefits of BW leading to purchase intention (Johnstone and Serret 2011; Klein and Huang 2008; Wilk 2006). Affective beliefs about BW's product image and symbolism were also positively related to purchase intention. Again, this finding also confirmed past research that reported how positive affective response toward image-laden BW advertising messages-highlighting youthfulness, fun and high-quality hydration choice as a status symbol-had helped facilitate purchase intentions (Cote and Wolfe 2018; Etale et al. 2018; Islam and Habib 2009). The importance of cognitive and affective beliefs as validated here also echoes the findings reported by a systematic literature review of creative media advertising effects (Eelen et al. 2016). This study suggested that when mediated by positive feeling and thoughts toward the brand, advertising can generate positive attitudes toward, word-of-mouth about and sales of a brand. By comparison, as advertising was found to strengthen positive brand associations over time, it was either an non-significant or negative factor in recall of product information (e.g., the factual knowledge in the current study context).

Turning to the TRA constructs, attitude was a positive and significant predictor of BW purchase intention, in line with the finding from previous studies (e.g., Bamberg and Möser 2007; Klöckner 2013; Morren and Grinstein 2016). With regard to perceived subjective social norms of BW consumption, this variable was also positively and significantly related to purchase intention. This finding thus validates past research that addressed the relations between subjective norms and different types of environmental behavior (Ahmad et al. 2016; Al-Swidi et al. 2014; Arl and Veysel Y1lmaz 2016). The combined findings which support consumer attitude and peer influence to be positive correlates to BW purchase intention are consistent with the assumption of TRA, which is a widely utilized theoretical model for explaining consumer behavior in the environmental conservation context.

\section{Conclusions}

The current study explores a set of theoretical factors-including knowledge, beliefs, attitudes, social norms and trust in BW advertising - to help explain young adults' bottled water purchase decision-making process. Consumers who trusted BW adverting more generally demonstrated more false knowledge about BW products and exhibited stronger beliefs about BW's health benefits and symbolic image - along with more favorable attitude and perceived social norms toward BW use-as well as a greater level of purchase intention. As companies invested heavily in advertising campaigns to make the claim that their BW product is of better quality and more desirable than tap water (Whitman 2016), they could cultivate consumer trust in their advertising narrative and hence trust in their brand over time.

By nature, consumers are creatures of habit (Bamberg et al. 2003) and will not stop purchasing the same product until a change in their perception and/or attitude toward that product is sufficient to alter their beliefs and behavior. The recent trend of "accessorizing" with a stylish reusable water bottles as a status symbol among millennials and the 20-somethings is an example of how consumers could be motivated to purchase a "conspicuously sustainability-conscious" product (Mull 2019). Previous research has already shown that status consciousness among consumers could encourage green product purchase when shopping in a public setting, especially when the green products are costlier than the non-green products under consideration (Griskevicius et al. 2010). Since $51.8 \%$ of the Generation- $Z$ college students surveyed in a national study indicated that they drank filtered water and nearly all of them agreed that BW packaging negatively impact the environment (Sudano 2018), it would be useful to disseminate social marketing campaigns that normalize carrying filtered water in a reusable water bottle as a "cool" and popular trend among younger consumers.

Several study limitations should be noted here. First, study participants were mostly white college students (68.9\%). Ideally, a more diverse and multiracial young adult sample 
could be studied in the future to increase generalization of the current findings. Second, lacking established scales or indices that measure factual vs. false knowledge in the literature, the study adopted an existing index (with preliminary empirical validation) to measure false knowledge and developed original items to assess factual knowledge. Even though these knowledge items, when tested in research questions and hypotheses, confirmed our theoretical assumptions, the clarity of these measurement items could be improved. Third, the study did not evaluate perceived descriptive norms and only measured perceived subjective norms (a TRA construct). Descriptive norms could be an important factor for examining consumption pattern among college students, as demonstrated in metaanalysis studies that assessed their alcohol use behavior (e.g., Armitage and Conner 2001; Rivis and Sheeran 2003).

As environmental attitude and awareness are major factors that can reduce consumer demand of BW and should be promoted through pro-environmental campaigns (e.g., van der Linden 2013), more scholarly research is needed to help formulate effective social marketing strategies that could reduce the purchase of bottled water. Future research could validate the current study findings with a more diverse emerging adult population. Additional studies could also test consumer trust in advertising strategies that promote reusable water bottles (and filtered tap water) as an alternative to purchasing bottled water. It would also be beneficial for future studies to explore the effectiveness of consumer trust in advertising messages in combination with BW knowledge measures that aim to reduce BW purchase among young adults in different marketing channels, especially the popular social media platforms. Young adults, including college students, remain a key consumer segment for this line of research. This is because, when properly motivated, they have the capacity to become social trend setters and could become avid environmental conservation advocates.

Author Contributions: Conceptualization, C.A.L. and X.X.; Methodology, C.A.L.; Survey Administration: X.X.; Statistical Analysis, C.A.L. and X.X.; Data Interpretation: C.A.L. and X.X.; Original Draft Preparation, C.A.L. and X.X.; Review \& Editing, C.A.L. and X.X. All authors have read and agreed to the published version of the manuscript.

Funding: This research received no external funding.

Institutional Review Board Statement: The study was conducted according to the guidelines of the Declaration of Helsinki, and approved by the Institutional Review Board of UNIVERSITY OF CONNECTICUT (protocol code H17-049, approved 18 March 2017).

Informed Consent Statement: Informed consent was obtained from all subjects involved in the study.

Data Availability Statement: The data are available upon request.

Conflicts of Interest: The authors declare no conflict of interest. 


\section{Appendix A}

Table A1. Measurement Items.

\begin{tabular}{|c|c|c|c|}
\hline $\begin{array}{c}\text { Variables (Explained } \\
\text { Variances) }\end{array}$ & Items & $\begin{array}{l}\text { Factor } \\
\text { Loading }\end{array}$ & $\begin{array}{l}\text { Alpha } \\
\text { Value }\end{array}$ \\
\hline $\begin{array}{l}\text { Trust in BW Adverts } \\
\text { (N/A) }\end{array}$ & $\begin{array}{l}\text { How much do you trust the information originated from the following } \\
\text { sources? "Bottled water adverts/commercials" (e.g., Dasani, Poland Spring, } \\
\text { Evian or Fiji). } \\
\text { (1 = Don't trust at all to } 7 \text { = Totally trust) }\end{array}$ & $\mathrm{N} / \mathrm{A}$ & $\mathrm{N} / \mathrm{A}$ \\
\hline $\begin{array}{l}\text { Cognitive Beliefs } \\
(65.02 \%)\end{array}$ & $\begin{array}{l}\text { I drink bottled water bought from a store because } \_(1=\text { Strongly Disagree } \\
\text { to } 7=\text { Strongly Agree }) \text { : } \\
\text { It tastes good. } \\
\text { It is clean. } \\
\text { It is from pure and natural water sources. } \\
\text { It is safe. } \\
\text { It contains ingredients good for health. }\end{array}$ & $\begin{array}{l}0.75 \\
0.73 \\
0.83 \\
0.66 \\
0.63\end{array}$ & 0.86 \\
\hline $\begin{array}{l}\text { Affective Beliefs } \\
(76.78 \%)\end{array}$ & $\begin{array}{l}\text { I drink bottled water bought from a store because }(1=\text { Strongly Disagree to } \\
7 \text { = Strongly Agree): } \\
\text { It looks cool to carry store-bought bottled water around. } \\
\text { I like the shape/design of the store-bought bottle. } \\
\text { I like the reputation of bottled water brands/companies. }\end{array}$ & $\begin{array}{l}0.66 \\
0.72 \\
0.92\end{array}$ & 0.85 \\
\hline
\end{tabular}

Please indicate whether the following statements are true or false $(0=$ False,

1 = True).

Most people consume a lot of bottled water. (False)

False Knowledge The regulations for producing bottled water are very strict. (False)

$(\mathrm{N} / \mathrm{A})$

Bottled water is originated from spring water in nature. (False)

$\mathrm{N} / \mathrm{A}$

$\mathrm{N} / \mathrm{A}$

Most people prefer bottled water over tap water. (False)

Most single-use water bottles are recycled into other useful products. (False)

Single-use bottled water is different from tap water. (False)

Single-use water bottles don't have much impact on the environment. (False)

Please indicate whether the following statements are true or false $(0=$ False,

$1=$ True)

The cost of getting an annual supply of bottled water is about 100 times more

than that for the same amount of tap water. (True)

There are stricter regulations for bottled water than for municipal tap water.

(False)

Factual Knowledge $(\mathrm{N} / \mathrm{A})$
Over-pumping of aquifers (i.e., a body of permeable rock that can contain or transmit groundwater) for producing bottled water has led to lowering of the water tables. (True)

It takes less amount of water to produce the bottle as it does to fill it (False).

Producing disposable plastic water bottles requires the use of millions of

barrels of oil. (True)

Over half of bottled water sold in the U.S. is tap water. (True)

Three of five single-use water bottles are recycled in the U.S. (False)

Attitude (70.53\%) ( $\quad(1=$ Strongly Disagree to $7=$ Strongly Agree $)$

I feel that consuming single-use bottled water: is a good habit.

0.90

I feel that consuming single-use bottled water: is good for my health. $\quad 0.71$

I feel that consuming single-use bottled water: suits my lifestyle. $\quad 0.81$

I feel that consuming single-use bottled water: makes me feel good 0.85

about myself.

0.68 
Table A1. Cont.

\begin{tabular}{|c|c|c|c|}
\hline $\begin{array}{c}\text { Variables (Explained } \\
\text { Variances) }\end{array}$ & Items & $\begin{array}{l}\text { Factor } \\
\text { Loading }\end{array}$ & $\begin{array}{l}\text { Alpha } \\
\text { Value }\end{array}$ \\
\hline \multirow{5}{*}{$\begin{array}{l}\text { Subjective Norm } \\
(78.48 \%)\end{array}$} & $(1=$ Strongly Disagree to $7=$ Strongly Agree $)$ & & 0.91 \\
\hline & $\begin{array}{l}\text { People in my social circle won't discourage me from purchasing single-use } \\
\text { bottled water. }\end{array}$ & 0.75 & \\
\hline & $\begin{array}{l}\text { People in my social circle approve of my frequent consumption of single-use } \\
\text { bottled water. }\end{array}$ & 0.93 & \\
\hline & People in my social circle support my preference for single-use bottled water. & 0.91 & \\
\hline & $\begin{array}{l}\text { People in my social circle won't be displeased, if I spend heavily on single-use } \\
\text { bottled water. }\end{array}$ & 0.77 & \\
\hline \multirow{11}{*}{$\begin{array}{l}\text { Purchase Intention } \\
(58.33 \%)\end{array}$} & $\begin{array}{l}\text { I plan to purchase bottled water, next time } \\
(1=\text { Strongly Disagree to } 7 \text { = Strongly Agree })\end{array}$ & & 0.92 \\
\hline & when I go run errands & 0.82 & \\
\hline & when I attend indoor events such as going to a movie or shopping mall & 0.70 & \\
\hline & when I exercise in the gym & 0.71 & \\
\hline & $\begin{array}{l}\text { when I attend outdoor events such as going to a football game or a baseball } \\
\text { game }\end{array}$ & 0.72 & \\
\hline & when I exercise outdoors, e.g., jogging or hiking & 0.75 & \\
\hline & when I order food at an eatery such as a deli, bakery, coffee shop or cafeteria & 0.67 & \\
\hline & when I buy grocery & 0.74 & \\
\hline & when I stop at a convenient store & 0.73 & \\
\hline & when I am thirsty & 0.68 & \\
\hline & when I go to school/work & 0.77 & \\
\hline
\end{tabular}

\section{References}

Abboud, Leila, and Judith Evans. 2020. Pandemic Adds to the Drain on Bottled Water. Available online: https://www.ft.com/content/ 981f3f16-9625-4c47-b67d-0a4dd23cbd79 (accessed on 17 July 2020).

Ahmad, Muhammad Shakil, Aqeel Ahmed Bazmi, Abdul Waheed Bhutto, Kanwal Shahzadi, and Nadia Bukhari. 2016. Students' Responses to Improve Environmental Sustainability through Recycling: Quantitatively Improving Qualitative Model. Applied Research in Quality of Life 11: 253-70. [CrossRef]

Ajzen, Icek. 1985. From Intentions to Actions: A Theory of Planned Behavior. In Action Control: From Cognition to Behavior. SSSP Springer Series in Social Psychology; Edited by Julius Kuhl and Jürgen Beckmann. Berlin/Heidelberg: Springer, pp. 11-39. [CrossRef]

Ajzen, Icek. 1991. The Theory of Planned Behavior. Organizational Behavior and Human Decision Processes. Theories of Cognitive Self-Regulation 50: 179-211. [CrossRef]

Al-Swidi, Abdullah, Sheikh Mohammed Rafiul Huque, Muhammad Haroon Hafeez, and Mohd Noor Mohd Shariff. 2014. The Role of Subjective Norms in Theory of Planned Behavior in the Context of Organic Food Consumption. British Food Journal 116: 1561-80. [CrossRef]

Alabi, Okunola A., Kehinde I. Ologbonjaye, Oluwaseun Awosolu, and Olufiropo E. Alalade. 2019. Public and Environmental Health Effects of Plastic Wastes Disposal: A Review. Journal of Toxicology and Risk Assess 5: 1-13.

Arı, Eekan, and V. Veysel Y1lmaz. 2016. A Proposed Structural Model for Housewives' Recycling Behavior: A Case Study from Turkey. Ecological Economics 129: 132-42. [CrossRef]

Armitage, Christopher J., and Mark Conner. 2001. Efficacy of the theory of planned behaviour: A meta-analytic review. British Journal of Social Psychology 40: 471-99. [CrossRef]

Bagozzi, P. Richard, Hans Baumgartner, and Youjae Yi. 1992. State versus Action Orientation and The Theory of Reasoned Action: An Application to Coupon Usage. Journal of Consumer Research 18: 505-18. [CrossRef]

Ballantine, Paul W., Lucie K. Ozanne, and Rachel Bayfield. 2019. Why Buy Free? Exploring Perceptions of Bottled Water Consumption and Its Environmental Consequences. Sustainability 11: 757. [CrossRef]

Bamberg, Sebastian, and Guido Möser. 2007. Twenty Years after Hines, Hungerford, and Tomera: A New Meta-Analysis of PsychoSocial Determinants of pro-Environmental Behaviour. Journal of Environmental Psychology 27: 14-25. [CrossRef]

Bamberg, Sebastian, Icek Ajzen, and Peter Schmidt. 2003. Choice of Travel Mode in the Theory of Planned Behavior: The Roles of Past Behavior, Habit, and Reasoned Action. Basic and Applied Social Psychology 25: 175-87. [CrossRef]

Biro, Andrew. 2019. Reading a Water Menu: Bottled Water and the Cultivation of Taste. Journal of Consumer Culture 19: 231-51. [CrossRef]

Brewis, Alexandra, Katie Meehan, Melissa Beresford, and Amber Wutich. 2021. Anticipating Elite Capture: The Social Devaluation of Municipal Tap Water Users in the Phoenix Metropolitan Area. Water International (March), 1-20. [CrossRef] 
Buzalka, Mike. 2016. Survey: Bottled Water Tops Gen Z Beverage Consumption. Food Management. Available online: https://www. food-management.com/news-trends/survey-bottled-water-tops-gen-z-beverage-consumption (accessed on 29 July 2021 ).

Chen, Di, Weiguo Qu, Yanhui Xiang, Jiaxu Zhao, and Guyu Shen. 2019. People of Lower Social Status Are More Sensitive to Hedonic Product Information-Electrophysiological Evidence from an ERP Study. Frontiers in Human Neuroscience 13: 147. [CrossRef] [PubMed]

Chung, Emily. 2020. What Really Happens to Plastic Drink Bottles You Toss in Your Recycling Bin I CBC News. CBC. Available online: https:/ / www.cbc.ca/news/science/bottle-recycling-1.5416614 (accessed on 7 January 2020).

Coleman, Linda Jane, Nisreen Bahnan, Mayuresh Kelkar, and Nicole Curry. 2011. Walking the Walk: How the Theory of Reasoned Action Explains Adult And Student Intentions To Go Green. Journal of Applied Business Research (JABR) 27: 107-16. [CrossRef]

Conway, Jan. 2020. Per Capita Consumption of Bottled Water in the U.S. 2019. Available online: https: / www.statista.com/statistics/ 183377 / per-capita-consumption-of-bottled-water-in-the-us-since-1999/ (accessed on 20 May 2021).

Cote, Stephanie, and Sarah Elizabeth Wolfe. 2018. Evidence of Mortality Salience and Psychological Defenses in Bottled Water Campaigns. Applied Environmental Education \& Communication 17: 281-98. [CrossRef]

Doney, Patricia M., and Joseph P. Cannon. 1997. An Examination of the Nature of Trust in Buyer-Seller Relationships. Journal of Marketing 61: 35-51.

Doria, Miguel de França, Nick Pidgeon, and Paul R. Hunter. 2009. Perceptions of Drinking Water Quality and Risk and Its Effect on Behaviour: A Cross-National Study. The Science of the Total Environment 407: 5455-64. [CrossRef]

Eelen, Jiska, Fabienne Rauwers, Verena M. Wottrich, Hilde A. M. Voorveld, and Guda van Noort. 2016. Consumer Responses to Creative Media Advertising: A Literature Review. In Advertising in New Formats and Media: Current Research and Implications for Marketers. Edited by P. De Pelsmacker. Bingley: Emerald Publishing, pp. 19-46. Available online: https://research.vu.nl/en/ publications / consumer-responses-to-creative-media-advertising-a-literature-rev (accessed on 20 January 2021).

Etale, Anita, Marilou Jobin, and Michael Siegrist. 2018. Tap versus Bottled Water Consumption: The Influence of Social Norms, Affect and Image on Consumer Choice. Appetite 121: 138-46. [CrossRef]

Ferrier, Catherine. 2001. Bottled Water: Understanding a Social Phenomenon. AMBIO: A Journal of the Human Environment 30: 118-19. [CrossRef]

Fitzmaurice, Julie. 2005. Incorporating Consumers' Motivations into The Theory of Reasoned Action. Psychology E Marketing 22: 911-29.

Foote, Marina Leigh. 2011. Examining Reasons for Bottled Water Consumption: A Case Study in Pensacola, Florida. Graduate thesis, University of South Florida, Tampa, FL, USA. Available online: http:/ /scholarcommons.usf.edu/etd/3106 (accessed on 20 January 2021).

Geerts, Robbe, Frédéric Vandermoere, Tim Van Winckel, Dirk Halet, Pieter Joos, Katleen Van Den Steen, Els Van Meenen, Ronny Blust, Elena Borregán-Ochando, and Siegfried E.Vlaeminck. 2020. Bottle or tap? Toward an integrated approach to water type consumption. Water Research, 115578. [CrossRef] [PubMed]

Griskevicius, Vladas, Joshua M. Tybur, and Bram Van den Bergh. 2010. Going Green to Be Seen: Status, Reputation, and Conspicuous Conservation. Journal of Personality and Social Psychology 98: 392-404. [CrossRef]

Ha, Hong-Youl, and Helen Perks. 2005. Effects of Consumer Perceptions of Brand Experience on the Web: Brand Familiarity, Satisfaction and Brand Trust. Journal of Consumer Behaviour 4: 438-52. [CrossRef]

Hawkins, Gay. 2017. The impacts of bottled water: An Analysis of Bottled Water Markets and Their Interactions with Tap Water Provision. WIREs Water 4: e1203. [CrossRef]

Hu, Zhihua, Lois Wright Morton, and Robert L. Mahler. 2011. Bottled Water: United States Consumers and Their Perceptions of Water Quality. International Journal of Environmental Research and Public Health 8: 565-78. [CrossRef]

International Bottled Water Association. n.d. Bottled Water Advertising. Available online: https:/ /bottledwater.org/bottled-wateradvertising/ (accessed on 20 May 2021).

Islam, Nazrul, and Md Wahidul Habib. 2009. Health Beliefs and Motivating Factors to Buy Bottled Water: A Case Study of the University Students of Bangladesh. SSRN Scholarly Paper ID 2850981. Rochester: Social Science Research Network. [CrossRef]

Johnson, Jim. 2019. Bottled Water Use Continues to Climb. Plastics News. Available online: https://www.plasticsnews.com/article/ 20190213/NEWS/190219930/bottled-water-use-continues-to-climb (accessed on 17 July 2021).

Johnson, Delaney R., and Jason R. Courter. 2020. Assessing Water Literacy at a Primarily Undergraduate University in Ohio. Natural Sciences Education, 49. [CrossRef]

Johnstone, Nick, and Ysé Serret. 2011. Determinants of Bottled and Purified Water Consumption: Results Based on an OECD Survey. Water Policy 14: 668-79. [CrossRef]

Jones, Catherine, Warwick E. Murray, and John Overton. 2017. FIJI Water, Water Everywhere: Global Brands and Democratic and Social Injustice. Asia Pacific Viewpoint 58: 112-23. [CrossRef]

Jorgensen, Bradley, Michelle Graymore, and Kevin O’Toole. 2009. Household Water Use Behavior: An Integrated Model. Journal of Environmental Management 91: 227-36. [CrossRef] [PubMed]

Jovarauskaitè, Lina, Audra Balundè, Inga Truskauskaitè-Kunevičienè, Goda Kaniušonytè, Rita Žukauskienė, and Mykolas Simas Poškus. 2020. Toward Reducing Adolescents' Bottled Water Purchasing: From Policy Awareness to Policy-Congruent Behavior. SAGE Open 10: 1-12. [CrossRef] 
Kim, Soojung, Se-Hoon Jeong, and Yoori Hwang. 2013. Predictors of Pro-Environmental Behaviors of American and Korean Students: The Application of the Theory of Reasoned Action and Protection Motivation Theory. Science Communication 35: 168-88. [CrossRef]

Klein, Christine A., and Ling-Yee Huang. 2008. Cultural Norms as a Source of Law: The Example of Bottled Water. Cardozo Law Review 30: $507-48$

Klöckner, Christian A. 2013. A Comprehensive Model of the Psychology of Environmental Behaviour-A Meta-Analysis. Global Environmental Change 23: 1028-38. [CrossRef]

Langdridge, Darren, Paschal Sheeran, and Kevin J. Connolly. 2007. Analyzing Additional Variables in The Theory of Reasoned Action. Journal of Applied Social Psychology 37: 1884-913. [CrossRef]

Levallois, Patrick, Jacques Grondin, and Suzanne Gingras. 1999. Evaluation of Consumer Attitudes on Taste and Tap Water Alternatives in Québec. Water Science and Technology 40: 135-39. [CrossRef]

Maloney, Jennifer. 2017. Soda Loses Its U.S. Crown: Americans Now Drink More Bottled Water. The Wall Street Journal. Available online: https:/ / www.wsj.com/articles/soda-loses-its-u-s-crown-americans-now-drink-more-bottled-water-1489082500 (accessed on 17 July 2021).

Manstead, S. R. Antony, and Dianne Parker. 1995. Evaluating and extending the theory of planned behaviour. European Review of Social Psychology 6: 69-95. [CrossRef]

Martin, Laura. 2003. Patterns of Bottled Water Consumption: A Review and Analysis. In Investigating the Environment. Edited by John Latto, Matt Orr and Manish Desai. Research for Environmental Management. Berkeley: University of California at Berkeley, Available online: https:/ / nature.berkeley.edu/classes/es196/projects/2003final/Martin.pdf (accessed on 20 January 2021).

Macias, Martin, Jr. 2018. Nestle's ‘Pure Life' Water Filled with Plastic, Class Says. Available online: https:/ / www.courthousenews. $\mathrm{com} /$ nestles-pure-life-water-filled-with-plastic-class-says / (accessed on 20 January 2021).

McAllister, Daniel J. 1995. Affect- and Cognition-Based Trust as Foundations for Interpersonal Cooperation in Organizations. Academy of Management Journal 38: 24-59.

McCarthy, Justin. 2017. In U.S., Water Pollution Worries Highest Since 2001. Gallup.Com. Available online: https:/ / news.gallup.com/ poll/207536/water-pollution-worries-highest-2001.aspx (accessed on 21 January 2021).

Menon, Ajit M., Aparna D. Deshpande, Matthew Perri III, and George M. Zinkhan. 2002. Trust in Online Prescription Drug Information among Internet Users: The Impact on Information Search Behavior after Exposure to Direct-to-Consumer Advertising. Health Marketing Quarterly 20: 17-35. [CrossRef]

Morren, Meike, and Amir Grinstein. 2016. Explaining Environmental Behavior across Borders: A Meta-Analysis. Journal of Environmental Psychology 47: 91-106. [CrossRef]

Mull, Amanda. 2019. How Fancy Water Bottles Became a 21st-Century Status Symbol. The Atlantic. Available online: https: //www.theatlantic.com/health/archive/2019/02/luxury-water-bottles/582595/ (accessed on 25 January 2021).

Nelson, Phillip. 1974. The Economic Value of Advertising. In Advertising and Society. Edited by Yale Brozen. New York: New York University Press, pp. 43-65.

Obermiller, Carl, and Eric R. Spangenberg. 1998. Development of a Scale to Measure Consumer Skepticism Toward Advertising. Journal of Consumer Psychology 7: 159-86. [CrossRef]

Philippe, Aurier, and Paul-Valentin Ngobo. 1999. Assessment of Consumer Knowledge and Its Consequences: A Multi-Component Approach. In NA-Advances in Consumer Research. Edited by Eric J. Arnould and Linda M. Scott. Provo: Association for Consumer Research, vol. 26, pp. 569-75.

PR Newswire. 2021. Bottled Water Market Size Worth \$505.19 Billion By 2028 ICAGR: 11.1\%: Grand View Research, Inc. 2021. Available online: https:/ / www.prnewswire.com/news-releases/bottled-water-market-size-worth-505-19-billion-by-2028--cagr11-1-grand-view-research-inc-301219764.html (accessed on 21 May 2021).

Peçanha, Sergio. 2020. “Opinion I Congrats! You Dump 100 Plastic Bottles in Nature Each Year.” Washington Post. Available online: https: / / www.washingtonpost.com/opinions /2020/02/19/congrats-you-dump-100-plastic-bottles-nature-each-year / (accessed on 20 May 2021).

Prasetiawan, Teddy, Anindrya Nastiti, and Barti Setiani Muntalif. 2017. 'Bad' Piped Water and Other Perceptual Drivers of Bottled Water Consumption in Indonesia. WIREs Water 4: e1219. [CrossRef]

Prevos, Peter. 2013. Bottled Water Marketing: The Importance of the Place of Origin. Available online: https://lucidmanager.org/ marketing/bottled-water-marketing/ (accessed on 30 May 2021).

Qian, Neng. 2018. Bottled Water or Tap Water? A Comparative Study of Drinking Water Choices on University Campuses. Water 10: 59. [CrossRef]

Rahman, Osmud, and Małgorzata Koszewska. 2020. A Study of Consumer Choice between Sustainable and Non-Sustainable Apparel Cues in Poland. Journal of Fashion Marketing and Management: An International Journal 24: 213-34. [CrossRef]

Rahman, Osmud, Benjamin C. M. Fung, and Devender Kharb. 2021. Factors Influencing Consumer Choice: A Study of Apparel and Sustainable Cues from Canadian and Indian Consumers' Perspectives. International Journal of Fashion Design, Technology and Education 14: 1-11. [CrossRef]

Rivis, Amanda, and Paschal Sheeran. 2003. Descriptive Norms as an Additional Predictor in The Theory of Planned Behaviour: A Meta-Analysis. Current Psychology 22: 218-33. [CrossRef]

Santos, Jessica, and Sander van der Linden. 2017. Environmental Reviews and Case Studies: Changing norms by changing behavior: The Princeton drink local program. Environmental Practice 18: 166-22. [CrossRef] 
Saylor, Amber, Linda Stalker Prokopy, and Shannon Amberg. 2011. What's Wrong with the Tap? Examining Perceptions of Tap Water and Bottled Water at Purdue University. Environmental Management 48: 588-601. [CrossRef] [PubMed]

Shotyk, William, Michael Krachler, and Bin Chen. 2006. Contamination of Canadian and European Bottled Waters with Antimony from PET Containers. Journal of Environmental Monitoring 8: 288-92. [CrossRef] [PubMed]

Soh, Hyeonjin, Leonard N. Reid, and Karen Whitehill King. 2009. Measuring Trust in Advertising. Journal of Advertising 38: 83-104. [CrossRef]

Stempel, Jonathan. 2019. Nestle to Face Lawsuit Saying Poland Spring Water Not from a Spring: U.S. Judge. Reuters. Available online: https: / / www.reuters.com/article/us-nestle-lawsuit-polandspring-idUSKCN1R92TO (accessed on 5 January 2021).

Sudano, Brian. 2018. Generation Z is Hammering The Final Nail in The CSD Coffin. Linkedin. Available online: https: / www.linkedin. $\mathrm{com} /$ pulse/generation-z-hammering-final-nail-csd-coffin-brian-sudano (accessed on 30 May 2021).

TAPP Water. 2018. How Many People Consume Bottled Water Globally? USA (blog). Available online: https://tappwater.co/us/howmany-people-consume-bottled-water-globally / (accessed on 5 January 2021).

The 2021 Axios Harris Poll 100. 2021. The Harris Poll. Available online: https://theharrispoll.com/axios-harrispoll-100/ (accessed on 30 May 2021).

Trumbo, Craig W., and Garrett J. O'Keefe. 2005. Intention to Conserve Water: Environmental Values, Reasoned Action, and Information Effects across Time. Society \& Natural Resources 18: 573-85. [CrossRef]

Tyson, Elic, Brian Kennedy, and Cary Funk. 2021. Gen Z, Millennials Stand out for Climate Change Activism, Social Media Engagement With Issue. Pew Research Center. Available online: https://www.pewresearch.org/science/2021/05/26/gen-z-millennialsstand-out-for-climate-change-activism-social-media-engagement-with-issue/ (accessed on 17 July 2021).

United States Environmental Protection Agency. 2021. Plastics: Material-Specific Data. Facts and Figures about Materials, Waste and Recycling. Available online: https://www.epa.gov/facts-and-figures-about-materials-waste-and-recycling/containers-andpackaging-product-specific-data\#PlasticC\&P (accessed on 17 July 2021).

Untaru, Elena-Nicoleta, Ana Ispas, Adina Nicoleta Candrea, Marcela Luca, and Gheorghe Epuran. 2016. Predictors of Individuals' Intention to Conserve Water in a Lodging Context: The Application of an Extended Theory of Reasoned Action. International Journal of Hospitality Management 59: 50-59. [CrossRef]

van der Linden, Sander. 2013. Exploring Beliefs about Bottled Water and Intentions to Reduce Consumption: The Dual-Effect of Social Norm Activation and Persuasive Information. Environment and Behavior 47: 526-50. [CrossRef]

van der Pligt, Joop, Marcel Zeelenberg, Wilco W. van Dijk, Nanné K. de Vries, and René Richard. 1997. Affect, Attitudes and Decisions: Let's Be More Specific. European Review of Social Psychology 8: 33-66. [CrossRef]

Vieux, Florent, Matthieu Maillot, Colin D. Rehm, Pamela Barrios, and Adam Drewnowski. 2020. Trends in Tap and Bottled Water Consumption among Children and Adults in The United States: Analyses of NHANES 2011-16 Data. Nutrition Journal 19: 10. [CrossRef]

Ward, Lorna A., Owen L. Cain, Ryan A. Mullally, Kathryn S. Holliday, Aaron G. H. Wernham, Paul D. Baillie, and Sheila M. Greenfield. 2009. Health Beliefs about Bottled Water: A Qualitative Study. BMC Public Health 9: 196. [CrossRef]

Whitman, Elizabeth. 2016. The Ad Campaign That Convinced Americans to Pay for Water. Priceonomics. Available online: http:/ / priceonomics.com/the-ad-campaign-that-convinced-americans-to-pay/ (accessed on 17 January 2021).

Wilk, Richard. 2006. Bottled Water: The Pure Commodity in the Age of Branding. Journal of Consumer Culture 6: 303-25. [CrossRef]

Xu, Xiaowen, and Carolyn A. Lin. 2018. Effects of Cognitive, Affective, and Behavioral Factors on College Students' Bottled Water Purchase Intentions. Communication Research Reports 35: 245-55. [CrossRef] 